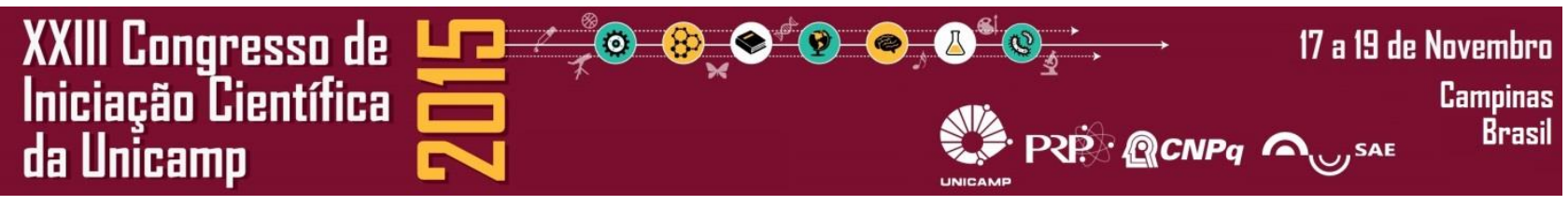

\title{
Análise quantitativa da liberação de íons fluoreto de materiais restauradores submetidos ao desafio cariogênico
}

\author{
Caroline P. Pinhatti (IC), Bruna C. Carrasco (IC), Alexsandra S. Iwamoto (PG), Raquel V. Rodrigues \\ (PG), Regina M. Puppin-Rontani (PQ), Fernanda M. Pascon (PQ).
}

\begin{abstract}
Resumo
Materiais restauradores que possuem íons fluoreto na composição apresentam vantagens para o sucesso do tratamento restaurador, por reduzir ou prevenir a desmineralização e promover a remineralização dos tecidos dentários pela liberação e recarga de fluoreto na cavidade bucal. Assim, faz-se necessária a investigação das taxas de liberação de fluoreto de diferentes materiais restauradores quando o conjunto esmalte/dentina/material restaurador é submetido ao desafio cariogênico.
\end{abstract}

Palavras Chave: Esmalte Dentário, Dentina, Compostos de Flúor.

\section{Introdução}

Cárie secundária é uma das principais razões para falhas das restaurações. Assim, materiais restauradores com fluoreto na composição, como cimento de ionômero de vidro, diminuem a progressão da cárie em pacientes de alto risco. Entretanto, devido a sinérise e embebição que afetam as propriedades físicas desses materiais, os cimentos de ionômeros de vidro modificados por resina foram desenvolvidos melhorando as propriedades e a longevidade da restauração. A capacidade de liberação de fluoreto dos materiais restauradores para a cavidade bucal varia de acordo com os mecanismos de união e da composição dos materiais. O objetivo do estudo foi avaliar in vitro a liberação de íons fluoretos a partir de restaurações em esmalte e dentina submetidas ao desafio cariogênico.

\section{Resultados e Discussão}

Cavidades foram preparadas em esmalte e dentina de dentes bovinos, distribuídas de acordo com o material restaurador $(n=10)$ : 1-Ketac Molar $^{\circledR}$ (3M/ESPE); 2-Vitremer ${ }^{\circledR}$ (3M/ESPE); e 3Filtek $Z 350^{\circledR}$ (3M/ESPE) e submetidas ao desafio cariogênico (6h em solução desmineralizadora + $18 \mathrm{~h}$ em solução remineralizadora, por 5 dias +2 dias em solução remineralizadora). A análise das soluções foram realizadas em duplicata, antes e após a ciclagem utilizando íon eletrodo específico e íon-analisador. Dados foram submetidos à ANOVA três fatores e ao teste de Tukey $(\alpha=5 \%)$. Para esmalte, observou-se diferença significativa entre os materiais $(p<0,01)$ e interação entre os fatores tempo $X$ solução $X$ material $(p<0,05)$. Em dentina, diferença significativa foi encontrada para os fatores tempo $(p<0,01)$, solução $(p<0,05)$ e material $(p<0,01)$, e somente foi observada interação entre fatores tempo $X$ solução $(p<0,01)$ e tempo $X$ material $(p<0,01)$.

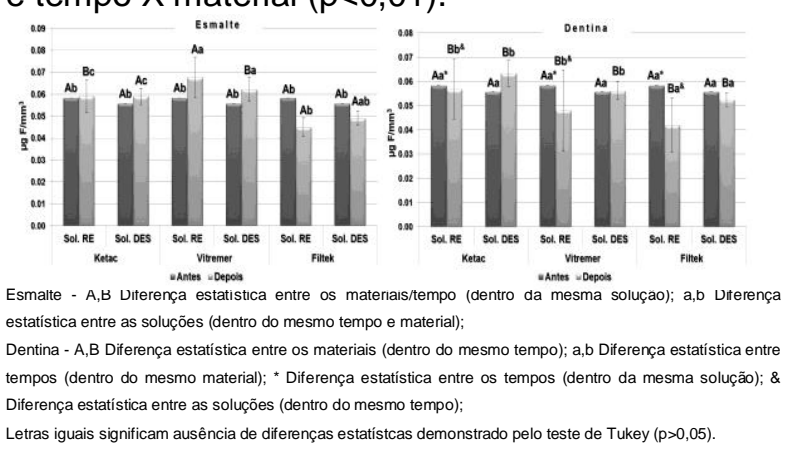

Figura 1. Média e desvio padrão da liberação de fluoreto pelos materiais restauradores antes e depois do desafio cariogênico em esmalte e dentina.

\section{Conclusões}

Conclui-se que o cimento de ionômero de vidro modificado por resina e o convencional apresentaram maiores taxas de liberação de fluoreto, em esmalte e dentina, respectivamente e que o desafio cariogênico influenciou nas taxas de liberação dos íons.

\section{Agradecimentos}

SAE/PIBIC

Basso, G. R.; Della Bona, A.; Gobbi, D. L. e Cecchetti, D. Fluoride release from restorative materials. Braz Dent J. 2011, 22, 355-8. Rodrigues, E.; Delbem, A. C.; Pedrini, D. e de Oliveira, M. S. PHcycling model to verify the efficacy of fluoride-releasing materials in enamel demineralization. Oper Dent. 2008, 33, 658-65.

Wiegand, A.; Buchalla, W. e Attin, T. Review on fluoride-releasing restorative materials--fluoride release and uptake characteristics, antibacterial activity and influence on caries formation. Dent Mater. 2007,23,343-62. 